\title{
Neotropical Spotted Cat Species Discrimination Using Morphometrics
}

\author{
Anne-Sophie Bertrand ${ }^{1 *}$ \& Antoine Morisot $^{2}$
}

\author{
${ }^{1}$ Biology Department, University of Aveiro, Aveiro, Portugal \\ ${ }^{2}$ Département Écologie \& Évolution, Université Paul Sabatier, Toulouse, France
}

\begin{abstract}
Leopardus cat species identification can be performed using footprints. We performed a discriminant function analysis on a data set of 52 Neotropical Spotted Cats (NSC) individuals from a Brazilian wildlife reserve. We isolated five morphometrics that wildlife biologists can use to identify the author of a track or footprint, i.e. total length, heel pad width, negative space (Lead toe to the front lobe of heel pad length), outer toe area and heel pad area. Our technique properly classified $94.2 \%$ of the individuals into the correct species, and $86.5 \%$ of cross-validated groups were correctly identified. By relying on measurable variables rather than the observer's ability to identify a species from a footprint, this technique will increase correct identification during track surveys, which will in turn help increase the accuracy of population inventories.
\end{abstract}

Key words: Morphometrics, Leopardus pardalis, L.tigrinus, L. wiedii, Footprints.

\section{Introduction}

Brazil shelters six felid species, three of which belong to the Leopardus genus (Oliveira \& Cassaro 1999). We will refer to these species as Neotropical Spotted Cats (NSC) as they all present spotted fur patterns, i.e., Ocelot (Leopardus pardalis), Oncilla (L. tigrinus), and Margay (L. wiedii; Figure 1). NSC are found in similar habitats, usually tropical and subtropical rainforests and dense vegetation areas (Oliveira \& Cassaro 1999). While larger felids are key species to the balance of ecosystems (Terborgh 1990), smaller felid species are also critical in controlling small prey populations (Konecny 1989). The growing anthropogenic habitat alterations, e.g. forest fragmentation, poaching, water/soil pollution, affect all Brazilian ecosystems and compromise their ecological services (Haines et al. 2005; Inskip \& Zimmermann 2009). Habitat disturbance is a common root cause to the NSC species declines (Caso et al. 2008; Oliveira et al. 2008; Payan et al. 2008).

NSC discrimination can be challenging as they have many similar attributes, e.g. habitats, morphology, behavior, ecology (Wang 2002), especially Margays and Ocelots (Haemig 2001; Oliveira et al. 2010). Haemig explained these similarities by the narrow phylogenetic links between them. Recent phylogenetic studies allowed separating these

*Send correspondence to: Anne-Sophie Bertrand Avenida Gramado, 2044, Jd. Lancaster, CEP 85869-160, Foz do Iguaçu, Paraná, Brazil

E-mail: annesophie@rede-verde.org close-relative species (Eizirik et al. 1998) and even reported hybridization cases (Trigo et al. 2008).

Implementing conservation projects on specific NSC species is difficult for several reasons. Solitary nocturnal habits and dense, often impenetrable habitat make NSC sightings rare events. Each data collection method has its pros and cons (Silveira et al. 2003). Telemetry studies are costly and generally based on a very small number of individuals (e.g. Konecny 1989). The reliability of camera-trapping data depends on the ability of the observer to distinguish species on photographs (Dillon \& Kelly 2008). When time allows, spoor surveys remain one of the most affordable methods for detecting and identifying felid species using footprints and track sets (Lewinson et al. 2001; Gusset \& Burgener 2005). However, results may vary depending on substrate quality, weather conditions and locomotion speed (Simonetti \& Huareco 1999) and this may interfere with the observer's ability to determine a species by its tracks (Smallwood \& Fitzhugh 1995; Grigione et al. 1999). Therefore, the reliability of data collected by any of these methods may be questionable (Frey 2006). Using a similar approach to what Lewinson et al. (2001) and more recently, García et al. (2010), have done with free-ranging and captive pumas (Puma concolor), the objective of this study was to verify the possibility of discriminating NSC species by a limited number of foot morphometrics, using a computerbased technique rather than relying on an observer's visual identification abilities. 


\section{Material and Methods}

\section{Study area}

The Itaipu Binacional's Wildlife Refuge is a facility sheltering several endangered species from inland Atlantic forest. It is located $30 \mathrm{~km}$ north of Foz do Iguaçu, state of Paraná, southwestern Brazil.

\section{Data collection}

We used a dataset of 52 captive adult specimens, genetically originating from the Iguaçu region. We drew the right fore foot outlines on a plastic board placed above footprints in sandy soil of 13 Ocelots, 21 Oncillas and 18 Margays. We then used SigmaScan Pro ${ }^{\text {tix }}$ to accurately obtain morphometrics from these outlines (Lewinson et al. 2001). We used linear, angular and area measurements as well as total length and width (Figure 2; Smallwood \& Fitzhugh 1993; Grigione et al. 1999; Lewinson et al. 2001; García et al. 2010). In total, we collected measurements of fifteen morphometric variables for each footprint (Appendix S1).

\section{Statistical analyses}

We tested normality using Kolmogorov-Smirnov test (García et al. 2010) and homogeneity of variance using Box's $\mathrm{M}$ test. As the purpose of a discriminant function analysis (DFA) is to predict membership in naturally occurring groups (Tabachnick \& Fidell 1983), we used it to identify the variables that could best categorize NSC individuals into species groups based on a selected set of morphometrics. Thus, we applied DFA to our data set of 52 individuals for which we calculated 15 distinct morphometric variables from their right fore feet. We evaluated the standardized discriminant function coefficients to identify the predictor

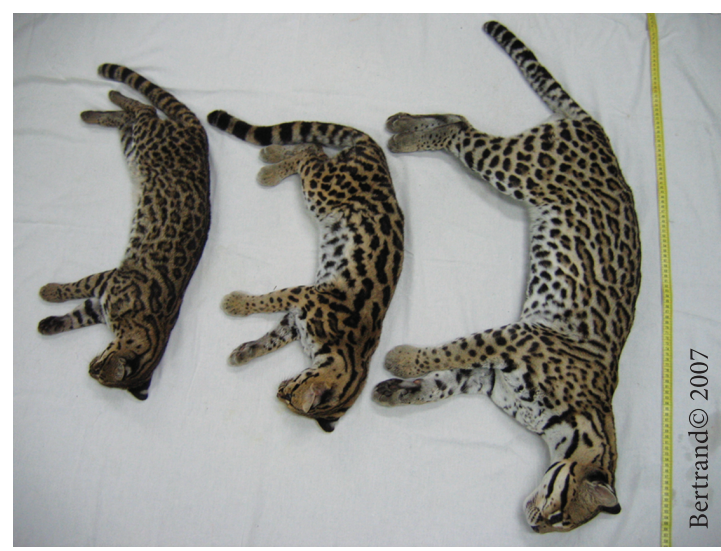

Figure 1. Comparison picture showing morphological specificities of each NSC species considered in this article. From left to right: Leopardus tigrinus, L. wiedii, and L. pardalis. Individuals are all captive adult males. Photograph was taken at the Itaipu wildlife refuge facilities. variables which explained most of the linear classification functions obtained. We verified the NSC species assignment using Wilk's Lambda test, matrices values and locations within the scatterplot (Lewinson et al. 2001). Among the initial list, we selected the morphometrics the most correlated to the two first discriminant functions from the structure matrix. We then conducted another DFA with the reduced set of morphometrics $\left(\mathrm{DFA}_{2}\right)$. The probability of misclassification of uncategorized cases was assessed using cross-validation (Hill \& Lewicki 2005). We used SPSS ${ }^{\mathrm{ra}} 15.0$ to perform all statistical analyses.

We evaluated the predictor variables that explained the most of the discriminant functions. We eliminated redundant predictor variables to reduce matrix ill-conditioning. We selected the variables with the largest absolute correlation with the discriminant functions in order to select a reduced number of morphometrics usable to discriminate NSC
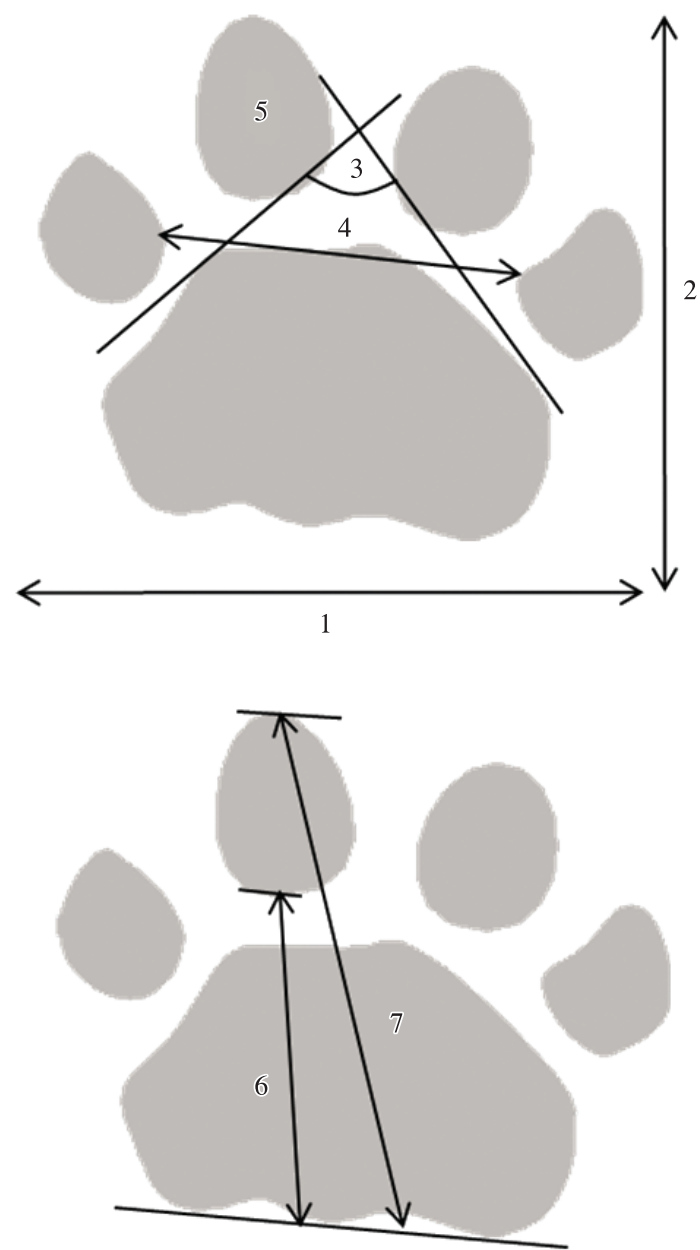

Figure 2. Linear and angular measurements characterizing NSC footprints. 1: Total width, 2: Total length, 3: Angle between inner toes, 4: Outer toe spread, 5: Width and length of lead toe, 6: Heel to lead toe length, 7: Negative space (Lead toe to the front lobe of heel pad length). The area of heel pad and each toe was also measured. 
species and develop an effective identification tool for wildlife biologists.

The discriminant coefficients of each morphometric of the model equation used to compute discriminant scores for each case are determined by the following discriminant function Equation 1:

$L=b_{1} x_{1}+b_{2} x_{2}+\ldots+b_{n} x_{n}+c$

where $L$ is the latent variable formed by the discriminant function, $b_{N}$ are the discriminant coefficients and $c$ is a constant.

\section{Results}

Using 15 morphometric measurements (Appendix S1), the first discriminant function explained $91.5 \%$ of total variance, and $100 \%$ of it could be explained by the two first canonical variables. All variables but one (i.e. negative space, Table 1) were strongly correlated to the first discriminant function. The five morphometrics that contributed the most to species discrimination were total length, heel pad width, negative space, outer toe area and heel pad area. In DFA 2 (Figure 3), $95.8 \%$ of total variance was explained by the first canonical discriminant function and the remaining with the second. $\mathrm{DFA}_{2}$ model allowed $94.2 \%$ of original grouped cases to be correctly classified while $86.5 \%$ of cross-validated groups were correctly classified.

\section{Discussion}

The classification model obtained with the five morphometrics most correlated to the two discriminant functions failed to classify correctly $5.8 \%$ of the original grouped NSC individuals. Two of the five selected morphometrics have been reported to best discriminate puma individuals by Smallwood \& Fitzhugh (1993), i.e. the outer toe spread and the heel pad width. Interestingly, Grigione et al. (1999) found that area measurements best discriminate individuals of a same species, with the exception of the heel pad area.

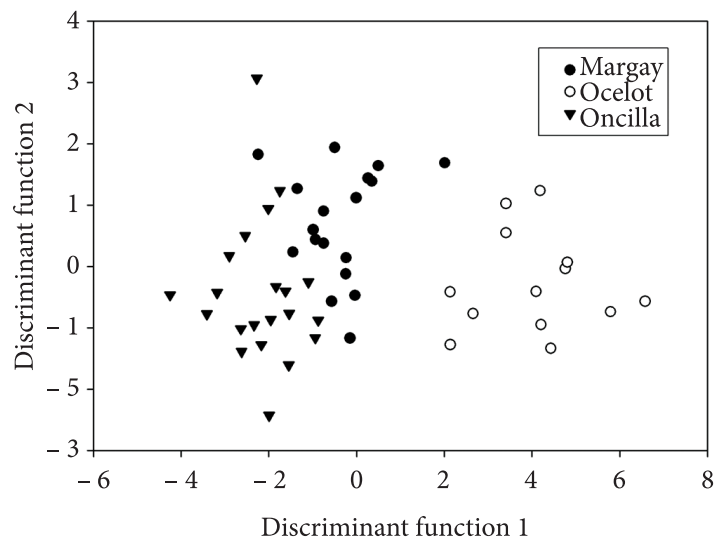

Figure 3. Scatterplot showing model performance in discriminating NSC individuals by species $(n=52)$.
This may suggest that heel pad area varies very little among individuals of a same species, which might explain why this morphometric is a component of our species classification model. When trying to discriminate males from females, García et al. (2010) found that the heel pad width, the inner toe area, the second toe area and the heel pad area provided the best results. Our data set contained both females and males of all three NSC species. Both the heel pad area and width contributed significantly to discriminate among species, suggesting that sexual size dimorphism also accounts for some of the species discrimination. Last, Lewinson et al. (2001)'s discriminant model for puma individuals included the outer toe spread, the heel to lead toe length and the angle between inner toes, which does not corroborate our findings for NSC species discrimination but their research focuses on pumas' rear feet.

Misclassification of cross-validated groups accounted for $13.5 \%$ of cases, most of which occurred between Margays and Oncillas. Hybridization between NSC species has been reported, especially where distribution ranges overlap due to environmental stress (e.g., food scarcity; Oliveira et al. 2008; Trigo et al. 2008). The morphometrics used to construct the classification model may need to be reviewed as hybridization progressively becomes a common event in NSC genetics. Meanwhile, the current model could help field NSC identification in $86.5 \%$ of cases, as long as footprints are clear enough to extract measurements for the five selected morphometrics. The application of such tool could thus improve the reliability of field NSC inventories used for conservation purposes (Frey 2006).

Table 1. Standardized discriminant scores ( $n=52$ cases).

\begin{tabular}{lcc}
\hline & \multicolumn{2}{c}{ Function } \\
\cline { 2 - 3 } & \multicolumn{1}{c}{$\mathbf{1}$} & $\mathbf{2}$ \\
\hline $\mathrm{LENGTH}$ & $0.803^{*}$ & 0.031 \\
$\mathrm{D} 4 \mathrm{~A} \dagger$ & $0.783^{*}$ & -0.177 \\
$\mathrm{PADW} \dagger$ & $0.749^{*}$ & 0.130 \\
$\mathrm{PADA} \dagger$ & $0.732^{*}$ & 0.045 \\
$\mathrm{D} 2 \mathrm{~A} \dagger$ & $0.720^{*}$ & -0.033 \\
$\mathrm{D} 1 \mathrm{~A} \dagger$ & $0.700^{*}$ & -0.107 \\
$\mathrm{PADL}$ & $0.696^{*}$ & -0.058 \\
$\mathrm{D} 3 \mathrm{~A} \dagger$ & $0.690^{*}$ & -0.260 \\
$\mathrm{D} 3 \mathrm{~L} \dagger$ & $0.642^{*}$ & -0.357 \\
$\mathrm{D} 1 \mathrm{D} 4$ & $0.639^{*}$ & 0.129 \\
$\mathrm{WIDTH} \dagger$ & $0.619^{*}$ & 0.069 \\
$\mathrm{PADD} 3$ & $0.595^{*}$ & 0.129 \\
$\mathrm{D} 3 \dagger$ & $0.583^{*}$ & -0.168 \\
$\mathrm{D} 2 \mathrm{D} 3$ & $0.269^{*}$ & 0.043 \\
$\mathrm{NEGSP}$ & 0.062 & $0.385^{*}$ \\
\hline
\end{tabular}

* Largest absolute correlation between each variable and discriminant functions. $\dagger$ Ln transformed variables. Variable code key: PADA) Heel pad area; D1A) Inner toe area; D2A: Second toe area; D3A: Third toe area; D4A: Outer toe area; PADW: Heel pad (maximum) width; PADL: Pad length; D3W: Third toe width; D3L: Third toe length; PADD3: Heel to lead toe length; NEGSP: Negative space (Lead toe to the front lobe of heel pad length); D1D4: Outer toe spread; LENGTH: Total length; WIDTH: Total width; D2D3: Angle between inner toes. 


\section{Management implications}

If the simple outline collection method and identification tool presented here were used in some of the many shelters and refuges worldwide, much needed data could quickly be available to wildlife biologists. Method can be applied to other species by developing a discriminant model based on footprints collected from adult captive specimens of the species of interest, prior to field collection. Obviously, field data collection is totally dependent upon the quality of substrate and weather conditions. However, when these conditions are favorable, species abundance can then be estimated from track surveys in the field (Rodriguez et al. 2000) and used to inform conservation strategies anywhere they are required.

While NSC species have been receiving more and more attention for the past two decades, their population statuses and extinction risks could not be clearly determined due to the lack of field data (Oliveira et al. 2008; Payan et al. 2008). Our field experience and the number of misidentifications found in educational and vulgarization science materials suggest a high probability for spreading erroneous information about these cats. Without a reliable, observerindependent identification tool, the IUCN Red List may be presenting inaccurate information on these confusing NSC species and their actual population statuses might be quite different from what they are thought to be (Rodrigues et al. 2006). Margays are listed as 'nearly threatened' by the IUCN with habitat destruction as one of the main threats (Payan et al. 2008). Yet in 2007, during telemetry monitoring in the study area, we found Margays in moderately to heavily-altered habitats (unpublished data). Oliveira et al. (2010) conducted a telemetry study in the region of Emas National Park and also found that Ocelots and other small cats used pasture and agricultural lands. Di Bitteti et al. (2010), who used camera-traps to look at habitat use and species occupancy patterns, also found that NSC, especially Margays and Oncillas, were relatively resilient to habitat disturbances. Lastly, one could rightfully question the validity of an identification tool based on tracks for the arboreal Margay species. Nonetheless, telemetry monitoring and camera-trapping have confirmed that Margays actually use the ground to move around and only occasionally use tree canopy (Konecny 1989; Di Bitteti et al. 2010).

Typical NSC behaviors do not normally allow direct observations. Footprints or track sets therefore represent a convenient tool for inferring population attributes and dynamics (Balmé 2005). The identification procedure presented here is innovative as it simplifies and increases the reliability of NSC species identification based on footprints. It does not rely on observation abilities, but rather on objective morphometrics. It can be used by anyone with some computer skills and greatly minimizes misidentification risks.

\section{Acknowledgements}

We are grateful to Itaipu Binacional and its Wildlife Refuge for providing access to their captive little spotted cats. We are also thankful to our field assistants for their help with field footprint data collection. Our warm thanks to Dr. Jim Sanderson from the Small Cat Conservation Alliance, IUCN Cat Specialist, for his comments on a prior version of this manuscript.

\section{References}

Balmé G, 2005. Counting cats. Africa Geographic, 36-43.

Caso A et al., 2008. Leopardus pardalis. In: International Union for Conservation of Nature - IUCN. IUCN Red List of Threatened Species. version 2011.2. Available from: <www. iucnredlist.org>. Access in: 19 May 2012.

Di Bitteti MS et al., 2010. Niche partitioning and species coexistence in a Neotropical felid assemblage. Acta Oecologica, 36:403-412. http://dx.doi.org/10.1016/j. actao.2010.04.001

Dillon A \& Kelly MJ, 2008. Ocelot home range, overlap and density: comparing radio telemetry with camera trapping. Journal of Zoology, 275:391-398. http://dx.doi. org/10.1111/j.1469-7998.2008.00452.x

Eizirik E et al., 1998. Phylogeographic patterns and evolution of the mitochondrial DNA control region in two neotropicals cats (mammalian, felidae). Journal of Molecular Evolution, 47:613-624. PMid:9797412. http:// dx.doi.org/10.1007/PL00006418

Frey JK, 2006. Inferring species distributions in the absence of occurrence records: an example considering wolverine (Gulo gulo) and Canada lynx (Lynx canadensis) in New Mexico. Biological Conservation, 130:16-24. http://dx.doi. org/10.1016/j.biocon.2005.11.029

García KP et al., 2010. Morphometrics of the tracks of Puma concolor: is it possible to differenciate the sexes using measurements from captive animals? Zoological Studies, 49:577-582.

Grigione MM et al., 1999. Identifying individual mountain lions Felis concolor by their tracks: refinement of an innovative technique. Biological Conservation, 88:5-32. http://dx.doi. org/10.1016/S0006-3207(98)00096-2

Gusset M \& Burgener N, 2005. Estimating larger carnivore numbers from tracks counts and measurements. African Journal of Ecology, 43:320-324. http://dx.doi. org/10.1111/j.1365-2028.2005.00581.x

Haemig PD, 2001. La ecologia del Ocelote y el Margay. Ecologia Info, n. 9. (in Spanish).

Haines AM et al., 2005. Evaluating recovery strategies for an ocelot (Leopardus pardalis) population in the United States. Biological Conservation, 16:512-522. http://dx.doi. org/10.1016/j.biocon.2005.06.032

Hill T \& Lewicki P, 2005. Statistics: Methods and Applications. Tulsa: StatSoft, Inc.

Inskip C \& Zimmermann A, 2009. Human-felid conflicts: a review of patterns and priorities worldwide. Oryx, 43:18-34. http://dx.doi.org/10.1017/S003060530899030X 
Konecny MJ, 1989. Movement patterns and food habits of four sympatric carnivore species in Belize, Central America. Advances in Neotropical Mammalogy, 1989:243-264.

Lewinson R, Fitzhugh EL \& Galentine SP, 2001. Validation of a rigorous track classification technique: identifying individual mountain lions. Biological Conservation, 99:313-321. http:// dx.doi.org/10.1016/S0006-3207(00)00197-X

Oliveira TG \& Cassaro K, 1999. Guia de identificação dos felinos brasileiros. 2nd ed. São Paulo: Sociedade de Zoológicos do Brasil.

Oliveira TG et al., 2008. Leopardus tigrinus. In: International Union for Conservation of Nature - IUCN. IUCN Red List of Threatened Species. version 2011.2. Available from: <www.iucnredlist.org >. Access in: 30 Apr 2012

Oliveira TG et al., 2010. Ocelot ecology and its effect on the small-felid guild in the lowland Neotropics. In Macdonald DW \& Loveridge A (orgs.). Biology and Conservation of Wild Felids. Oxford: Oxford University Press. p. 563-584.

Payan E et al., 2008. Leopardus wiedii. In: International Union for Conservation of Nature - IUCN. IUCN Red List of Threatened Species. version 2011.2. Available from: <www. iucnredlist.org>. Access in: 30 Apr 2012.

Rodrigues A et al., 2006. The value of the IUCN Red List for conservation. Trends in Ecology \& Evolution, 21:71-76. http://dx.doi.org/10.1016/j.tree.2005.10.010

Rodriguez JP et al., 2000. Local data are vital to worldwide conservation. Nature, 403:241. PMid:10659822. http:// dx.doi.org/10.1038/35002183

Silveira L, Jacomo ATA \& Diniz-Filho JAF, 2003. Camera trap, line transect census and track surveys: A comparative evaluation. Biological Conservation, 114:351-355. http:// dx.doi.org/10.1016/S0006-3207(03)00063-6

Simonetti J \& Huareco I, 1999. Use of tracks for assessing diversity and relative abundance of mammals in the Beni Biosphere Reserve-Biological Station, Bolivia. Mastozoología Neotropical, 6:139-144.

Smallwood K \& Fitzhugh E, 1993. A rigorous technique for identifying individual mountain lions Felis concolor by their tracks. Biological Conservation, 65:51-59. http://dx.doi. org/10.1016/0006-3207(93)90196-8

Smallwood KS \& Fitzhugh EL, 1995 A track count for estimating mountain lion Felis concolor Californica population trend. Biological Conservation, 71:251-259 http://dx.doi. org/10.1016/0006-3207(94)00034-N

Tabachnick BG \& Fidell LS, 1983. Using multivariate statistics. Harper and Row.

Terborgh J, 1990. The role of felid predators in neotropical forests. Vida Silvestre Neotropical, 2:3-5.

Trigo TC et al., 2008. Inter-species hybridization among Neotropical cats of the genus Leopardus, and evidence for an introgressive hybrid zone between L.geoffroyi and L.tigrinus in southern Brazil. Molecular Ecology, 17:4317-4333. PMid:18785898. http://dx.doi. org/10.1111/j.1365-294X.2008.03919.x

Wang E, 2002. Diets of Ocelots (Leopardus pardalis), Margays (L. wiedii), and Oncillas (L. tigrinus) in the Atlantic rainforest in southeast Brazil. Studies on Neotropical Fauna and Environment, 37:207-212 http://dx.doi.org/10.1076/ snfe.37.3.207.8564

Received: May 2012

First Decision: May 2012

Accepted: June 2012 